\title{
2 \\ Diabetes, risk management, and the birth of modern primary care
}

Although the creation of the NHS had strengthened the role of hospitals in diabetes management, a minority of innovative practitioners began to experiment with more community-oriented care schemes in the 1950s. Clinics and local government health departments cooperated to extend the surveillance and educative reach of clinicians, with nursing and health visiting staff forming part of expanded care teams. With their growing mix of skills, the new teams sought to confront the myriad social and medical problems facing patients with a common chronic disease.

These arrangements had generally marginalised GPs. Many GPs either lacked confidence with the condition (referring sole responsibility for diabetic problems to clinics) or, reflecting wider tensions within the profession, did not have patients returned to them by hospital colleagues, who lacked faith in GPs' capabilities. Moreover, whilst some GPs undoubtedly assumed a significant amount of responsibility for diabetes care, divisions of labour with hospitals were rarely systematised. Responding to a Ministry of Health questionnaire issued in 1963, one consultant physician from Caerphilly summarised a situation common across Britain: 'on the whole, G.P.s [sic] prefer to leave the care of diabetics to the clinic and none has expressed special interest [in patients with the condition].'

Despite such trends, within ten years of this assessment a host of systems and research programmes emerged around general practice and shared care in diabetes. Into the 1980s, many hospital practitioners remained sceptical about the abilities of GPs, and evaluations of new organisational arrangements highlighted numerous problems. Yet innovations spread in face of such difficulties, with novel patterns of GP-led and community-based care reaching from Stirling to Poole and from Powys to King's Lynn. ${ }^{2}$ 
This chapter explores how GPs became enrolled in novel diabetes management programmes, and why schemes for integrated care spread across the country. At its heart, the chapter positions the changing organisation of diabetes care within professional political projects. For hospital consultants, the attractions of co-operating with GPs were clear. Patient numbers were outstripping hospital resources, with the result that clinicians felt standards of care were falling. Moreover, the politicisation of hospital costs and waiting times during the 1960s and 1970s meant that conditions in clinics could no longer be tolerated. With local government health departments atrophying, the greater incorporation of GPs in systematic diabetes care offered a way to alleviate pressures on clinics, spreading the cost of care and freeing consultants to focus on the patients who they believed were in most need of skilled oversight. ${ }^{3}$ Consultants also suggested that GPs would be able to provide more attentive care than clinics to patients whose management was deemed more 'routine'. These were patients who were generally not on insulin regimes, who had no long-term complications, and who did not regularly experience hypoglycaemia or significant hyperglycaemia. As such, they were also patients whose straightforward oversight proved less clinically challenging or interesting.

By contrast, the motivations of GPs to involve themselves in diabetes care are less obvious on first sight. Diabetes management increased their clinical work, with no compensatory increase in resources, and there were more prevalent 'chronic illnesses' that could have drawn GPs' attention. ${ }^{4}$ Of course, many GPs became involved in diabetes care because they believed standards could be improved. Diabetes management, however, also tied neatly into the shifting politics of general practice following the 1950s, and became incorporated into broader efforts to improve the status of GPs within the profession and British health services. The first appeals for greater GP involvement, for instance, emerged in relation to pre-symptomatic disease and prevention, areas of considerable interest to some GPs, especially those connected with academic institutions. By the early 1970s, poor-quality evidence and cost concerns had seen such claims superseded, with GP care entangled in long-held discussions about the unique social, psychological, and clinical skills of GPs. Finally, appeals to preventive risk management returned alongside the themes of practice organisation in the 1980s and 1990s, as bodies like the Royal College of General Practitioners (RCGP) incorporated diabetes care into projects of quality assurance and public health practice. Diabetes, in other words, became a disease 
more feasibly managed in general practice because of changes in the institutional environment, but it was also a disease around which general practice could be remade in ways consonant with broader professional projects.

Such endeavours cannot be divorced from post-war political and economic developments. The spectre of cost-control - and related calls for greater service integration and efficiency - haunted debates. New schemes for diabetes were part of wider NHS readjustments, particularly in chronic disease care, and diabetes management provided something of a 'model' for other chronic conditions. ${ }^{5}$ Similarly, this chapter suggests that ground-breaking schemes would not have been possible without determined pioneers and important technological innovations. Particularly in the 1960s and 1970s, structured GP care for diabetes was rare, and integrated schemes tended to emerge where local clinicians and GPs either were especially interested in the condition or were convinced by persuasive colleagues.

Bringing these factors into a single analysis will articulate the rich political, professional, and technological histories underpinning important shifts in British diabetes management. The reorganisation of responsibilities for diabetes could involve conflict or even founder upon passive resistance, and in the short term GP involvement in structured care schemes was geographically uneven. However, the extent of occupational and institutional change involved in new arrangements was significant enough to raise awkward questions. GPs and hospital practitioners alike became concerned about standards of care and the possibility of dividing and integrating labour across time and space. As will be explored in Chapter 3, the answers that doctors produced to these challenges had repercussions for medical professionals and for the status of diabetes as a 'model' chronic disease. Likewise, the ways in which managed labour become aligned with public health policy is taken up in the rest of the volume. To understand the magnitude of these changes, however, it is important to first have a sense of the landscape of care in the 1950s.

GPS and diabetes management in the first decade of the NHS

Although the referral system had a long lineage, the creation of the NHS confirmed and generalised the role of the GP as part personal doctor, part gatekeeper. ${ }^{6}$ Most GPs lost or dropped private practice work after 1948 , instead serving registered populations of up to 4,000 patients in 
the new service. ${ }^{7}$ Registered patients could access a GP for consultation whenever they felt it necessary - generally upon experiencing symptoms - either by making an appointment (though this was rare before the 1960s), receiving a home visit, or simply waiting at the practitioners' surgery. Upon attendance, GPs would diagnose problems and prescribe treatment for patients who they thought were within their competence and means (with wide variation), referring on to hospital those who they felt required special investigations or therapy. ${ }^{8}$ In principle, any test results, diagnoses, or treatment plans made at hospital would be explained to the GP via a letter on discharge, thereby ensuring that the GP had a complete medical history of the patient for future contact. Although ideals were only patchily realised, patient access to costly hospital services were mediated through these mechanisms of registration and referral, and the GP became the primary medical contact for patients over their lifetime.

In diabetes care, the introduction of the NHS also accelerated interwar trends. Despite specialist diabetes outpatient clinics growing after the 1920s, the financial arrangements of the inter-war medical system were complex. Patients could avoid direct charges for diagnostic tests, medical consultation, and therapeutic agents under certain conditions, but not under others. Access to clinics (and even GP care) thus varied across the country. The NHS, however, removed most financial barriers to hospital care for patients. Moreover, its generalisation of capitation payments for general practice meant that GPs would also have no monetary incentive to keep hold of patients making heavy demands on their time, as was the case with patients with diabetes. ${ }^{9}$ In general, therefore, patients with diabetes were the perfect candidates for referral, and a significant proportion of GPs passed all diabetes care on to specialists. ${ }^{10}$

Financial factors in referral were buttressed by intra-professional aversions and anxieties. On a local level, consultant staff and GPs could maintain good relations, but the existence of private medicine often helped to facilitate friendly co-operation. ${ }^{11}$ In terms of diabetes, some GPs even served as 'clinical assistants' in specialist outpatient clinics, undertaking clinical assessments and consultation under direction of senior hospital doctors. ${ }^{12}$

Broadly speaking, though, hospital doctors did not hold general practice in high regard during the 1950s. Despite the fact that general practice provided the most likely employment after qualification, one survey undertaken in 1961 indicated that only one quarter of 'senior medical students and newly-qualified doctors' made general practice 
their first-choice occupation. ${ }^{13}$ The views of junior practitioners seemed to dovetail with, and be shaped by, the values expressed by senior doctors. Taking one frequently cited example, Lord Moran, the President of the RCP, suggested to a Royal Commission on pay in 1958 that GPs were generally doctors who had 'fallen off' the professional 'ladder.' ${ }^{14}$ These opinions generated considerable backlash, and Lord Moran later attempted to modify his statement. By contrast with hospital specialties, entrance into general practice required no vocational training during the late 1950s, with a pre-registration year in hospital practice considered sufficient for a graduate to be appropriately qualified. ${ }^{15}$ Referring to this difference, Lord Moran claimed that his initial statement was meant only to support the rewarding of lengthy specialist training. ${ }^{16}$ Nonetheless, the underpinning sentiment was telling, and seemingly common within diabetes care. Surveys of doctors from the late 1950s indicated that clinicians did not always trust GPs to be skilled or confident enough to look after patients with diabetes, and specialist liaison after referral could be poor. ${ }^{17}$ During the 1960s, hospital doctors complained that 'few general practitioners are prepared to treat their diabetic patients', the consequence of which was retention of clinic attenders 'indefinitely.'

However, a minority of GPs did retain almost complete responsibility for their patients with diabetes during the 1950s and 1960s. ${ }^{19}$ One well-known practitioner suggested that he referred only sixteen of eighty maturity-onset patients under his care over twenty years. ${ }^{20}$ Furthermore, during the 1950s at least, most GPs retained some contact with their diabetes patients. Though highlighting a significant rate of attrition from formal care, one review conducted between 1952 and 1954 estimated that GPs saw approximately 68 per cent of their patients with diabetes annually. ${ }^{21}$ Such findings were supported by an earlier study, which recorded an average of around eight consultations with these patients per year, albeit with a wide range across locations (between two and fourteen consultations per year) and age (higher rates for patients aged sixty-five and above). ${ }^{22}$

Yet, whilst regular contact was not uncommon, most consultations were not for management of diabetes per se. GPs may have been responsible for initial disease detection, but, following referral, clinics often assumed the lead in diabetes care, and patients contacted community care staff for more quotidian issues, such as daily drug administration or treatment of unrelated illness. ${ }^{23}$ In fact, reflecting on her contact with GPs over twenty years between 1960 and 1980, one patient recalled 
that 'apart from perhaps mentioning it [her diabetes] if I went to him with any other problem, it never seemed to be brought forward at all. ${ }^{24}$ It was a common arrangement, and not just for diabetes. Once patients had been referred or admitted to hospital, specialist services often retained managerial responsibility for patients with supposedly complicated long-term illness. ${ }^{25}$ One prominent report from the 1960s even referred to these outpatients as 'detainees. ${ }^{26}$ As such a critical assessment suggests, this division of labour between hospital specialist and GP was soon to be placed under question.

Early challenges in the 1960s: co-ordinating care, risk, and pre-symptomatic disease

The earliest calls for a reorganisation of responsibility and labour in diabetes management came from a handful of GPs, hospital clinicians, and public health practitioners during the 1960s. All these doctors recognised the importance and advantages of specialist outpatient clinics in their usual respects: laboratory facilities, experienced physicians, cutting-edge research, and availability of ancillary services. ${ }^{27}$ Yet, for this tiny minority of critics from across the medical spectrum, overwhelming support for specialist outpatient clinics masked important problems. The first, according to clinicians like John Nabarro at the Middlesex Hospital, was that once a patient was referred, there was 'a tendency for the entire treatment to pass to the clinic'. Problems could arise, he concluded, 'when the practitioner is called in, in an emergency', as 'he [sic] is without up-to-date knowledge of the patient's condition and treatment. ${ }^{28}$ The second common concern amongst critics was the ever-growing size of clinic populations. Busy conditions made comprehensive care very difficult. 'The crowded diabetic clinic', wrote the well-known academic clinician, researcher, and diabetologist Harry Keen, 'is not the place where the deeper or more confidential of the diabetics' problems may be easily unfolded.' Rather, he suggested, diet and insulin were the 'chief preoccupations' of the 'busy clinic', despite being 'only the beginning of the diabetic life. ${ }^{29}$

Indeed, the causes and results of the clinic's problems were summarised succinctly by one GP from the Birmingham region (L. A. Pike) at a joint meeting of MOHs and GPs in the early 1960s:

At the present time, it seems to be the rule that a patient with suspected diabetes is referred to hospital where the diagnosis is confirmed. The 
diabetic clinic then takes the patient under its wing and never lets him [sic] go. Rarely are patients discharged to their family doctor, and of course many family doctors are prepared to delegate this care. The general practitioner copes with illnesses other than diabetes and advises the patient between hospital visits. Clinics serve a valuable function in the assessment of new cases, the management of severe diabetes, and as centres for research and teaching. In my area, however, I feel that these functions are hampered by the deluge of diabetics who turn up to keep their routine appointments but who could well be supervised by their family doctor. In most places the diabetic clinics are working to capacity with a shortage of staff and premises.

With the estimated prevalence of diabetes rising, the author concluded, 'resources are going to be further stretched by the increasing number of diabetics particularly in the older age groups. ${ }^{30}$

These criticisms would be heavily repeated into the 1970s, and they drove many of the initial experiments with more formal programmes for shared care. During the 1960s, however, hospital clinicians, GPs, and $\mathrm{MOH}$ suggested several solutions to the issue of overcrowding. Harry Keen, for instance, sought to promote roles for GPs as surveillance officers: 'It is a common experience for the diabetic', Keen wrote, 'noting the approach of his [sic] visit to the clinic, to tighten up his control.' As doctors relied on short-term measurements of urine and blood glucose, this meant that when the patient arrived at the clinic, they 'present[ed] an excellent and thoroughly atypical picture of it [their diabetic control]'. Being able to check on patients between visits to the hospital, Keen suggested, GPs could circumvent such strategies, proposing that 'no-one is better situated to assess the degree of control of the diabetic than the family doctor. ${ }^{31}$ Moreover, unburdened by the busy strictures of the clinic, the GP, Keen also implied, might be better placed to deal with the social, psychological, and emotional concerns of patients - with the patient's 'employment problem, his fears about blindness, his sexual impotence, or the veil of prejudice he has met at work. ${ }^{32}$ Whilst the hospital dealt with the 'technical' matters of therapy, GPs could take up responsibility for the broader challenges of chronic disease. ${ }^{33}$ No formal programme was forthcoming, however.

GPs who were critical of existing arrangements often sought a more substantive role, primarily for those 'well-controlled' patients who did not require specialist attention or technologies. ${ }^{34}$ 'There is no reason why', wrote Pike, in a partnership practice the control of diabetes should not be undertaken by one of the partners in the way that 
maternity work is sometimes undertaken. ${ }^{35}$ In addition to managing already diagnosed patients, Pike also envisioned a greater role in casefinding and preventive medicine. Drawing on the Birmingham detection survey, he ruled out mass screening on grounds of expense. Instead, 'greater results will be obtained with less effort' if practitioners focused on those considered 'at-risk' ${ }^{36}$ In this case, vigilance would be applied to individuals who had relatives with diabetes, who were over fifty years old (especially women over this age), who were obese (or, owing to higher prevalence at different weights, 'lighter' if 'West Indian'), who were multiparous or had a history of giving birth to babies over $10 \mathrm{lb}$, or who had classic symptoms of diabetes. Such characteristics, according to Pike, might be predictive of diabetes either because population research revealed these groups to contain a disproportionate number of people with diabetes than in control groups (e.g. the under-fifties or the non-obese), or because retrospective study revealed that such characteristics were preponderant amongst people who developed diabetes. ${ }^{37}$ Moreover, transitioning from statistical prediction to causative concepts of risk, Pike viewed targeted case-finding as necessary because intervention before symptoms became 'marked' offered the best hope of preventing complications. ${ }^{38}$

For more radical interlocutors, such work would form part of an expanded GP role in chronic disease surveillance more broadly. For instance, according to R. F. L. Logan of the innovative Darbishire House research team at the University of Manchester, screening studies had unlocked new areas of research and practice activity. "Where 300 persons in an average practice', he argued, 'may have a glucose tolerance test so abnormal that classically it would be considered diabetic, it makes us ask the questions: What is diabetes? When does the disease begin?' The part played by GPs in such investigations meant that 'general practice is now at the front line of these fundamental questions about the nature of non-infectious disease itself and the point of its onset. ${ }^{40}$ Moving on to practicalities, Logan suggested that as many conditions were multi-causal 'you cannot have primary prevention of them. ${ }^{\text {, }}$ Instead, intervention would focus on secondary and tertiary prevention. Thus, in the 'medical care of the chronic non-infectious pattern of disease today', Logan suggested, 'the poles of curative medicine on the one side and prevention on the other no longer apply'. Rather, 'what do apply are, early presymptomatic recognition, surveillance of high risks, postponing the onset or reducing its impact, bringing in of adequate care, delaying of handicap, and training residual abilities. ${ }^{, 2}$ 
For conditions like diabetes, hypertension, glaucoma, rheumatoid arthritis, cancers, and mental illnesses, Logan felt that 'something directly effective, often life-saving can be done in general practice.' ${ }^{3}$ And even though undertaking care and 'surveillance in the control of chronic disease' could 'swamp' the GP - especially in the context of population growth and rising 'expectations of the lower social classes' - organisational solutions could ensure success. Primarily, change would involve drastic reductions in home visiting, and the GP becoming a 'community doctor' with a large list, 'a team of nurses', and 'a centre equipped with modern facilities. ${ }^{44}$ To use David Armstrong's terms, Logan sought to turn the GP into the embodiment of dispensary medicine: ever watchful of the whole population, not just locating 'submerged' clinical disease but redrawing the boundaries between health and illness in the process. ${ }^{45}$

That academics like Logan were key figures in promoting new understandings of disease and service provision is indicative of the way the NHS provided a productive environment for research and scholarly activity. As Valier and Timmermann have argued, the regional structure of the NHS, based on 'major teaching hospitals and their affiliated universities', provided post-war academics with abundant research opportunities and considerable intellectual influence within the profession. ${ }^{46}$ Research and education were initially less integral to establishing authority in general practice, but the situation slowly changed over the 1950s and 1960s. ${ }^{47}$

Nonetheless, unfortunately for Logan, his vision was far removed from the experience of most GPs, and problems of workload, finances, and prominent understandings of disease worked against the creation of new roles for general practice. Some recent service changes may have facilitated novel forms of care. A new GP contract had been agreed in the mid-1960s which extended allowances for administrative, nursing, and other staff. ${ }^{48}$ Similarly, some innovative $\mathrm{MOH}$ were keen to attach their staff to GP surgeries, conceptualising the future of public health activity in relation to so-called 'lifestyle diseases' and health service management. ${ }^{49}$ Yet, as one respondent to Logan's paper put it, 'medical time, manpower and finance are limited. ${ }^{50}$ 'Although regular effective screening of the community may be a theoretical ideal', the author went on, 'there is a very real danger of forgetting the amount of disease that is and can be prevented by the conventional methods which depend on nature's early warning system [of symptoms] and which are the keystone of good general practice. ${ }^{51}$ Furthermore, not only did many 
doctors still take symptoms (rather than asymptomatic, quantitative deviations) as the starting point of disease, but clinicians and researchers across the health services also felt that evidence was insufficient to categorically support screening and pre-symptomatic intervention. ${ }^{52}$

In terms of clinical diabetes, there were further obstacles to remaking the role of GPs along preventive lines. The power of metabolic control to protect against longer-term complications was still a matter of dispute during the 1960s, and one tempered by the very practical fear of hypoglycaemia, the inconveniences of testing, and desires for a normal life. ${ }^{53}$ With uncertainty about the effects of glycaemic control even for the symptomatic, surveillance and opportunistic lifestyle advice represented the furthest practitioners would go for 'at risk' or 'borderline' patients whilst further research was ongoing. ${ }^{54}$ Similarly, whilst medical civil servants were intrigued by the implications of community surveys for screening and diagnostic criteria, they made little movement beyond committee discussions. ${ }^{55}$

In short, economies of time and finance, combined with persistently high opinions of specialist practice, curtailed more systematic general practice interventions into diabetes management during the 1960s. Such arguments did not disappear. Rather they became background to further discussion until changes in knowledge, ideology, and health service conditions made them more persuasive.

\section{Expanding GP care: integration and deputation in the 1970s}

At the heart of discussions about GPs and diabetes care during the 1960s were questions about the nature of disease and general practice, about the use of resources, and - as will be noted later in this chapter - about the very structure of the NHS itself. Critically, such discussions were taking place within a context of shifting political and financial circumstances of the health service. As noted in Chapter 1, since its inception, the health service had been under severe pressures to control costs. Negotiations between the Ministry of Health and the Treasury did secure significant capital investment for the NHS during the 1960s as part of the political renewal of central planning. ${ }^{56}$ Furthermore, supported by the findings of the now-famous Guillebaud Report in 1956, the NHS also received a real-terms increase in current expenditure over the 1960s, funded in part by an erratically expanding economy. ${ }^{57}$ Nonetheless, central pressures to use resources efficiently and to cap current expenditure remained in place. They were even formally agreed in 
exchange for increased capital investment in the nation's ageing hospital stock..$^{58}$

State drives to control NHS expenditure also extended to encouraging greater professional engagement with questions of resource use. In 1966, the Ministry of Health and Joint Consultants Committee of the British Medical Association established the Joint Working Party on the Organisation of Medical Work in Hospitals. ${ }^{59}$ Its reports sought to provide the basis for collective professional governance of hospitals prior to possible service restructuring. Linking individual decision-making to collective resources, the first report suggested that 'practically every clinical decision affects the administrative running of the hospital'. Effective management - 'the smooth and economic running of the procedures concerned with diagnosis, treatment and care' - would thus depend upon 'mobilising the full consciousness of clinicians about the effect of their individual actions on others than the patient. ${ }^{60}$ In 1953, the Ministry had encouraged local medical advisory committees to 'undertake periodic ... systematic review and statistical analysis of the clinical work of all departments in the hospital', but without great success. ${ }^{61}$ Now the Working Party suggested improving routine data collection and organising consultant staff in 'clinical divisions' to carry out 'constant appraisal of the services it provides, [to] deploy clinical resources as effectively as possible and [to] cope with the problems of management that arise in its clinical field. ${ }^{62}$ Divisions would be linked via a small medical executive committee, with a senior clinician as chair, to ensure cross-institutional co-ordination. Though not compelling codification of work and performance management review, such reforms did facilitate greater professional oversight of work, and even saw institutions develop clearer guidelines for 'routine' hospital procedures. ${ }^{63}$

Such pressures intensified into the 1970s. Industrial unrest, rising inflation, growing unemployment, and confused policy responses brought down the Conservative administration of 1970-74. ${ }^{64}$ The incoming Labour government also had to cope with global economic turbulence, and the persistent mistrust of subsequent Labour administrations (1974-79) on the part of international capital markets resulted in a now infamous International Monetary Fund loan in $1976 .{ }^{65}$ These political and economic circumstances provided fertile ground for the spread of neoliberal ideas into British politics. ${ }^{66}$ During the 1970s, however, continued frustration with a lack of central control over NHS spending drove interest in increased service planning and management, 
and underlined persistent structural reforms that began in $1974 .{ }^{67}$ Labour administrations even developed a new planning and priorities system for the NHS in 1976, within which central government detailed the money available for specific objectives, and the hierarchy of health authorities then produced plans for resource allocation. 'Superior' authorities provided 'priorities and an indication of the resources available', and 'the 'inferior' authorities produc[ed] plans after consultation', with subsequent review up the chain of command. ${ }^{68}$

Central government departments were not the only policy actors to raise concerns about the use of NHS finances. Driven by older concerns about efficiency and new interests in health economics and patient consumerism, think-tanks and organised consumer groups like the King's Fund, the Nuffield Provincial Hospitals Trust, the Office of Health Economics, and the Patients' Association also raised public concerns about outpatient waiting times and hospital inefficiencies. ${ }^{69}$ In particular, they called attention to the large number of chronic patients - like those with diabetes - who they felt were unnecessarily attached to specialist clinics. ${ }^{70}$

Under such circumstances, criticisms of clinics grew louder during the 1970s. For some GPs, the problems of clinics resulted in unsatisfactory care for doctor and patient. As one GP wrote in 1974, once a patient was referred, they were 'doomed to take time off work, travel and wait to see a fresh houseman at almost every attendance ... His [sic] notes get thicker and thicker so that both [the patient] and the young doctor find the fleeting consultations more and more unrewarding. ${ }^{71}$ The very raison d'être of the clinic - continuous specialist care for individual patients - had become undermined, and specialists themselves complained about compromised management and worsening experiences of care. As one commentator put it, this was an ironic consequence, whereby the 'desire by hospital doctors to look after interesting patients has now backfired'. Instead of improving working conditions, the accumulation of patients had produced 'overcrowding' and the 'aims of treatment were being increasingly frustrated." ${ }^{72}$

What emerged in the 1970s, therefore, was a synergy of interests between GPs and hospital specialists within a febrile political environment. Building on early critiques, both saw mass outpatient care as costly and as failing patients. The figure causing problems, according to both sides, was the 'well-controlled' patient, with no long-term complications, who was being treated by diet alone (or diet and oral hypoglycaemic agent) and who attended the clinic for 'routine' follow-up. ${ }^{73}$ 
Their care had become rote for hospital practitioners, based on the periodic repetition of standard tests and, probably, advice to carry on in the same way. They also, according to one prominent clinician, prevented consultants from 'deal[ing] with the difficult problems for which [they had] been trained. ${ }^{74}$

Such patients sat at the heart of new programmes for more structured diabetes care and a new division of responsibilities for patient management. Incorporating a small, though growing, minority of GPs and consultants, schemes emerged in the first half of the 1970s to integrate GPs into formal diabetes management operations. Broadly speaking, the new arrangements followed from the criticisms of traditional clinic systems. GPs assumed ongoing responsibility for routine surveillance of uncomplicated and well-controlled patients. They monitored physical and biochemical health, watched for signs of complications, and made small adjustments in therapeutic programmes. Clinics were then reserved for most insulin-requiring patients, patients referred for complications, and individuals with 'brittle' diabetes (characterised by wildly fluctuating blood sugars). As will be shown in Chapter 3, the most systematic of these schemes formalised the responsibilities of the GP and clinic in new care protocol, complete with referral criteria, and clinics would see only new and referred patients or undertake yearly reviews.

There were, of course, variations between schemes. For instance, early programmes were predicated on clinic staff visiting general practice surgeries. These arrangements were pioneered during the late 1960s in the Birmingham area, where they were promoted by the nationally renowned diabetologist John Malins in conjunction with a handful of interested GPs. The role of the GP here focused upon involvement in annual review clinics that were now taking place in GP surgeries. Practice and clinic staff would undertake the necessary testing together, and then the patient would have a consultation with the GP and hospital doctor to agree a treatment plan. ${ }^{75}$

These arrangements persisted into later decades but were quickly challenged. ${ }^{76}$ Outside annual reviews, it seems that routine oversight continued to be un-organised. Other clinicians and GPs therefore built on these foundations to provide greater involvement and freedom for the GP. A particularly popular alternative emerged in the West Midlands city of Wolverhampton during the early 1970s. This system was created by the consultant P. A. Thorne - who, probably due to geographical proximity or the $\mathrm{BDA}$, was in contact with Malins - and 
focused on general practice 'mini-clinics'. Here (in line with Pike's suggestion above) one GP in a partnership would take responsibility for surveillance of all of a practice's diet-controlled patients. Special monthly 'mini-clinics' were then organised, in which doctors and nursing staff set aside protected time to review a select number of patients at regular intervals. The usual tests and consultations would take place, and no further contact with the clinic was deemed necessary unless a GP made referrals or organised a yearly visit to the surgery by the clinic team. ${ }^{77}$ GPs were given greater responsibility than in alternative plans, but were also more integrated into formal arrangements of care as a result.

One final notable form of systematic care was devised in the southern coastal town of Poole, Dorset. Like most of the early structured care schemes, the Poole system was driven by an influential and determined consultant working in tandem with engaged local GPs. For the consultant clinician R. D. Hill, his 'community care scheme' was more integrated than even the mini-clinic variety. Here, individual GPs kept responsibility for ongoing oversight of their own patients, but also coordinated surveillance activities with a range of community care workers - health visitors, opticians, and district nurses. As with miniclinics, GPs retained responsibilities for routine care adjustments, and hospital laboratory facilities were made open to all scheme members, but hospital staff undertook yearly reviews within the clinic. ${ }^{78}$ Although differing slightly, all the above arrangements sought to bring GPs into closer contact with hospitals and facilitate dispersal of duties. Each form, however, afforded slightly different weightings to continuity of care across certain areas of patient management.

Yet, for GPs, the attraction of diabetes care in the 1970s went beyond providing better care for their patients or improving NHS efficiency. Rather, by this decade systematic diabetes management appeared a more feasible proposition, and had become entangled with new visions of general practice itself. On the one hand, the increase in 'open access' arrangements for laboratory services over the 1960s enabled better patient surveillance, whilst familiarity with oral drugs bolstered GPs' confidence about treatment options. ${ }^{79}$ Equally, at a local level, good relationships between GPs and charismatic consultants enabled collective ownership of new arrangements. In Poole, for instance, Hill earnestly wrote to all GPs to ensure they were involved in the planning process for his community care system. ${ }^{80}$ 
On the other hand, pioneers of systematic care schemes discussed diabetes management in ways that harnessed the frustrations of some GPs and envisioned new positions for them in British medicine. During the 1960s, many GPs expressed dissatisfaction with treating high levels of what they saw as minor illness in their practices. In one survey of GPs, for instance, one quarter of the 400 respondents believed that over 50 per cent of their surgery consultations were for 'trivial, unnecessary, and inappropriate reasons. ${ }^{, 81}$ Anxieties over the status of general practice were thus not uncommon, and proponents of GP-based care framed diabetes management as an absorbing area of clinical medicine. According to Malins and a GP colleague, taking on diabetes patients would prove satisfying, primarily because the GP 'no longer feels that the clinical care of an interesting disease is being taken from him [sic] ${ }^{82}$ Equally, another GP, promoting systematic care of diabetes by GPs alone, declared how he hoped to 'convey the idea that small numbers of patients suffering from the same disease, as occur in general practice, can provide a wide spectrum of experience in symptomatology, pathology and treatment. ${ }^{83}$ These authors sought to make capital out of dissatisfaction, emphasising how diabetes could keep a doctor's interest and advertising the ways in which diabetes management intersected with highly valued areas of clinical medicine.

By contrast, other GPs drew on languages of personalised and continuous care of individuals and families to promote diabetes care. Although having a long heritage, these ideas gained considerable currency in the decades after the 1950s, as bodies like the College of General Practitioners (later the RCGP) sought to position them at the heart of GPs' professional identities. ${ }^{84}$ The College itself had been established in 1952-53, by a group of doctors keen to mould general practice into an independent discipline with its own skills and knowledge. ${ }^{85}$ The new body emerged, moreover, at a time when the creation of the NHS, and extensive criticisms of general practice's standards of provision, had damaged the morale of GPs, provoking a period of sustained reflection on the 'essence' and role of general practice in British medicine. ${ }^{86}$ Over the early post-war decades, professional bodies and central state agencies alike sought to objectify general practice and to study it in order to understand its nature, and launched formal commissions to plan for its future. $^{87}$

The contrast between the GP and the hospital doctor was a central element in all reflections on general practice. Whereas the clinician 
dealt with advanced cases of disease in abstract and artificial spaces, the GP treated patients in 'natural' settings of home, community, and surgery. ${ }^{88}$ Furthermore, perhaps responding to claims that the NHS was too bureaucratic or impersonal, and hoping to differentiate GPs without detriment to status, some commentators revived a rhetoric that distinguished GPs by their personal knowledge of patients and their ability to build relationships over time. ${ }^{89}$ One well-regarded practitioner considered this longitudinal bond to be so strong that, he suggested: 'the GP alone can offer the patient, and his family continuity of medical care over the years. They alone can know the family environment. And they alone can learn what is normal for the individual patient. ${ }^{90}$

Appeals to personalised practice continued into the 1970s, and medical individualism underpinned claims about general practice diabetes care in that decade. ${ }^{91}$ Promoting their scheme for GP-based annual reviews, for instance, Malins and Stuart outlined how patients welcomed the innovation. Not only was review closer to home, they argued, but patients were 'glad to come into an atmosphere which is familiar and to be greeted by staff whom they know. They feel that during the consultations their personal and social circumstances are fully taken into account.' According to Malins and Stuart, GPs would also benefit by gaining new expertise and would be more readily accepted as competent by patients with diabetes. ${ }^{92}$ Similarly, Thorn and Russell argued that as a result of GPs taking responsibility for diabetes, general patient care would no longer pass to the clinic, and the care of the 'whole patient' would return to GPs. ${ }^{93}$ In fact, being able to take personal and social circumstances into account now made sense for GPs as well. As some articles thus claimed, the combination of 'social and emotional problems' with symptoms, physical, and biochemical changes made diabetes clearly 'of interest' to the GP. ${ }^{94}$

\section{Consolidating new arrangements: prevention and diabetes management}

Over the next two decades, appeals for more systematic and integrated diabetes care shifted once again, moving in line with newer visions for general practice. Into the $1980 \mathrm{~s}$, discussions of general practice diabetes management returned to themes of prevention, organisation, and anticipatory care, with the psycho-social discourses of the 1960s and 1970s appearing as minor themes. By this decade, moreover, the questions posed in major medical publications were less concerned with 
whether GPs 'should' have a greater involvement in care, and focused instead on the form that this care could take.

In some respects, doctors in the 1980s revisited questions posed during the 1960s. As noted, a handful of elite and academic practitioners had previously sketched out a vision for GPs as preventive risk managers, but GPs ultimately felt that limitations of evidence and resources made such roles impossible. In terms of diabetes, themes of risk management and prevention reappeared during the 1980s. However, discussions of risk centred on programmes for secondary and tertiary prevention of diabetic complications rather than on primary disease prevention. For instance, during the 1970s several follow-up reports on 'borderline' diabetes appeared that extinguished much interest in these patients for several decades. Firstly, clinical trials found that instituting treatment in borderline patients did not seem to alter their physiological prospects: regardless of intervention, a small minority 'worsened to diabetes', whilst many more either returned to normal or remained the same over five to ten years of study. ${ }^{95}$ Secondly, researchers noted that 'borderline' patients were at greater risk of cardiovascular and arterial disease than 'normal' controls. Yet, once again, anti-diabetic treatment appeared to make little impact on clinical outcomes, and statistical analyses suggested that heightened blood pressure was more likely than hyperglycaemia to underpin higher rates of arterial disease. ${ }^{96}$ Thus, whilst researchers argued that 'impaired' glucose tolerance could be considered a state of risk - and its physiological abnormalities were worthy of follow-up at the extreme end - they concluded that it was neither a diabetic nor pre-diabetic state, and could not be clinically reversed..$^{97}$ Clinicians continued to discuss monitoring individuals with impaired glucose tolerance and those considered at risk for diabetes. But such action was intended to facilitate early diagnosis and treatment for all who required it, rather than to be a means of preventing the onset of disease. ${ }^{98}$

By contrast, over the 1980s, doctors were increasingly convinced that maintaining good blood glucose control might prevent the onset of complications. Much of this support was built on findings from largescale longitudinal studies of defined populations, combined with clinical research with 'borderline cases. ${ }^{99}$ Specifically, this research suggested that the diagnostic category of diabetes should be restricted to those individuals whose blood sugar levels two hours after glucose intake were over $200 \mathrm{mg}$ per $100 \mathrm{ml} .{ }^{100}$ From follow-up investigations of initial prevalence surveys, researchers argued that characteristic pathological 
changes of the retina could be found almost exclusively in populations with readings above this blood glucose level on initial examination. ${ }^{101}$ Not all patients (as they became) with this level of blood glucose developed retinopathy during the study period. Nonetheless, these findings were considered statistically significant, and offered a pathological marker with which to differentiate between populations with gradated variations in blood glucose.

Once doctors applied this knowledge in a clinical setting, they transformed a diagnosis of diabetes into an exercise of risk management and surveillance. ${ }^{102}$ Whilst there was no guarantee that any one individual would develop retinopathy, the statistical argument for formalising standard diagnostic criteria at this level proved convincing. ${ }^{103}$ Though it was not explicitly stated in publications, the extension of this logic meant that diagnosis was necessary to integrate patients into formal management and surveillance programmes - ones designed to reduce risk via hypoglycaemic interventions, and to deploy new technologies to treat retinal complications upon first indications of their appearance. ${ }^{104}$ As we have seen, these arguments were not entirely novel: interviewees suggested that some doctors presumed a link between complications and control before these studies, on 'the balance of probabilities. ${ }^{105}$ However, whereas previously diagnosis may have depended upon the presence of symptoms - or a hypothetical assumption about the relationship between hyperglycaemia and complications - diagnosis now became predicated upon precise statistical calculations of likelihood derived from large-scale datasets, and individual treatment was formally legitimated by this research's predictive possibility. ${ }^{106}$

The relationship between British doctors and international diagnostic standards will be considered further in Chapter 5. However, it is important to note here that discourses of risk management and patient surveillance became a key part of discussions of GP care. For some GPs and hospital clinicians, new epidemiological research confirmed a link between diabetes and long-term complications, corroborated by their clinical experience and some smaller-scale clinical trials. ${ }^{107}$ As one GP put it, 'good diabetic control is most important in preventing complications', and though 'extra time is needed to run a clinic', 'diabetics are such a high-risk group tha[t] an average of five minutes per day for prevention and treatment is an efficient use of a doctor's time.'108

Indeed, a tighter net of surveillance provided by integrated and systematic care would ensure that this secondary preventive effort 
could be a complemented by tertiary effort to prevent blindness. As will be seen in Chapter 4, new evidence about the efficacy of photocoagulation therapy in certain types of diabetic retinopathy sparked a push for new treatment programmes. In the words of one widely cited account, this development created a new imperative for tighter surveillance: 'retinopathy is a serious complication which can cause blindness; new treatments are being developed, so early detection is increasingly important. ${ }^{109}$ Such statements found further support amongst proponents of integrating hospital and general practice care. Here, 'regular monitoring of ... glycaemic control, weight, blood pressure' and 'a screening programme for the early detection of the long-term complications of diabetes' were essential activities. Research on defaulting and outcomes in the 1980s indicated that much scope existed for greater organisation and for 'rationalisation of care' and surveillance across the system. ${ }^{110}$

Yet it is important to note that changed discourses around GP diabetes care during the 1980s were not sparked solely by new research evidence unveiling incontestable truths. Instead, motivated by clinical, professional, and political imperatives, doctors and other health policy actors made numerous assumptions that were not strictly supported by available research. Firstly, the clinical interpretation of new evidence was not entirely consistent with what research had demonstrated. Though studies in the 1990s would support efforts to control blood glucose (and other risk factors), the publications of the late 1970s and early 1980s demonstrated only statistically significant, positive correlations between hyperglycaemia and selected end-points over time. ${ }^{111}$ They did not, in other words, conclusively exclude the possibility of a hidden factor provoking both raised glucose levels and complications, or prove positive outcomes would result from intervention. ${ }^{112}$ Secondly, though it was assumed that more refined disease surveillance would improve outcomes, it took until 1985 for a study to suggest that defaulters had worse physiological markers and complications than clinic attenders, and follow-up work was rare. ${ }^{113}$ As with earlier research in coronary heart disease, it seems that clinical imperatives for intervention infused reactions to these observational studies, and medical desire to help transformed risk from a marker of prediction to a causative-butmodifiable variable. ${ }^{114}$

Just as importantly from the perspective of general practice, proactive work in diabetes became of wider interest as GPs made a more 
concerted effort to move into preventive medicine, and as the RCGP sought to promote better practice organisation. ${ }^{115}$ Regardless of the technical validity of their interpretation (from within the bounds of trial-oriented thinking), for a small number of GPs new evidence about complications facilitated professional efforts to reposition diabetes care as a public health endeavour. The lead here was taken by the RCGP itself. Although not pronouncing on diabetes management formally during the 1970s, the College's Journal provided significant space for discussion of diabetes care. College support became explicit in the early 1980s, when a working party called for 'routine management of hypertension and non-insulin-dependent diabetes [to] be brought back to general practice. ${ }^{116}$ The justification for this recommendation did not focus solely on clinical experience or benefits that might accrue to patients and practitioners. ${ }^{117}$ Rather, the College suggested that people with diabetes were a population 'at exceptional risk for arterial disease', and that the 'control of known diabetics in respect of blood glucose, obesity, smoking, and hypertension' would improve outcomes. ${ }^{118}$ The benefits of 'preventive effort', it suggested, would 'flow naturally from improved clinical care.. ${ }^{\text {'19 }}$ As will be noted in later chapters, aligning clinical work with preventive medicine in this way would have considerable implications for the political future of managed care.

Diabetes management, therefore, played a symbolic part in broader efforts to incorporate GPs into new public health arrangements. The discussions on diabetes, for instance, came from one of five College working parties considering the role of the GP in health promotion and public health. Their recommendations were unsurprising considering the group's composition. Julian Tudor Hart, a GP working in south Wales, was chair, and was well known for promoting GPs as key figures in the prevention and management of chronic disease on a community basis. ${ }^{120}$ Similarly, other members included Laurie Pike (quoted above), and Godfrey Fowler, a GP in Oxford who worked in an academic department of community medicine and general practice and who edited a volume entitled Preventive Medicine in General Practice shortly after the publication of the arterial disease report. ${ }^{121}$

The move to establish GPs in preventive medicine situated discussions of diabetes within frameworks of chronic disease management more broadly. Concepts of risk management as a form of secondary and tertiary prevention had first emerged in relation to discussions of 'chronic disease' during the 1960s. Furthermore, the management of 
conditions like hypertension, though involving different symptomatic patterns from diabetes, experienced similar changes in understanding during the post-war period, whilst pharmacological innovations for other long-term diseases, like asthma, had also made their care more routine. ${ }^{122}$ Following such developments and the growth of patient populations, GPs sought to claim responsibility for ongoing care from specialist clinics, or at least to share in management duties. By the 1980s, general practice had been framed as ideally suited for the management of chronic disease', and doctors even considered the application of similar models of care to different problems. ${ }^{123}$ Discussing group practices, for instance, Hart proposed that 'the expected number of patients may justify concentration in regular mini-clinics for hypertension, diabetes, chronic obstructive airways disease, epilepsy, [and] rheumatic diseases'. Common approaches were possible, Hart suggested, because management of all these conditions had become centred on 'monitoring ... a set of variables, support by ancillary staff with at least some special training, the use of equipment not usually used, and giving patients information. ${ }^{\text {, }}{ }^{14}$ Here a form of care honed in diabetes management was generalised to other conditions, but the flow of influence could also work in the other direction, and doctors outlined how diabetes care in some sites had been altered in light of experience from other conditions. ${ }^{125}$ Underpinning such exchanges, however, were a desire to maintain contact with patients and a belief that continuing care of chronic disease in general practice could help prevent mortality, severe morbidity, and disability. ${ }^{126}$

Once again, however, it is important to place professional developments in the context of contemporaneous political and health service change. The 1970s and 1980s were decades in which economic turbulence and global programmes to address disease reinvigorated attitudes to prevention within primary care. Internationally, Marc Lallonde (Minister of National Health and Welfare, Canada) gave his famous set of talks on prevention and responsibility in 1974, and the World Health Organization (WHO) placed prevention at the heart of primary care in the influential Alma-Ata Declaration of 1979. In Britain, economic problems provided grounds for reassessing how prevention might lessen burdens on the state, and Labour's subsequent policy papers on prevention not only drew on Lallonde's work, but also provoked the RCGP's own re-examination. ${ }^{127}$

Equally, these same financial pressures and shifts in thinking had, in part, influenced the reorganisation of the NHS in 1974, which provided 


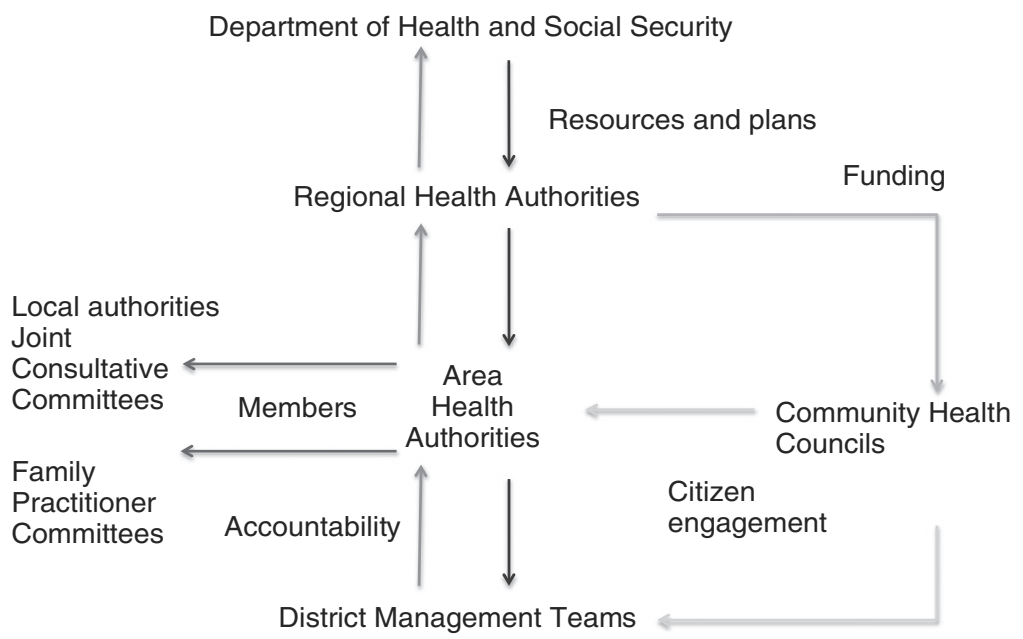

Figure 2.1 Representation of English NHS as envisioned after 1974 reorganisation

the conceptual and institutional space for GPs to move into preventive healthcare. ${ }^{128}$ Undoubtedly, the schemes discussed above drew strength from the languages of integrated health and social service planning that characterised debates about reform during the 1960s and 1970s. The working party on medical work discussed above also sought to integrate service planning and management by including GPs in clinical divisions. However, the biggest impact of the 1974 reform on diabetes care came from the abolition of the MOHs as part of broader ambitions for service unification. The reforms played out slightly differently across Britain. In England, new legislation for the NHS eliminated the previous 700 bodies involved in administration, and established in their stead 14 Regional Health Authorities (RHAs), 90 Area Health Authorities, 90 Family Practitioner Committees, and 205 District Management Teams (see Fig. 2.1).

In Scotland, the development of a new settlement ran faster and more smoothly than south of the border, with a less overt emphasis on management and greater stress on political partnership with health authorities. ${ }^{129}$ The system was considerably more centralised - with common services organisations providing plans and advice to integrated health 


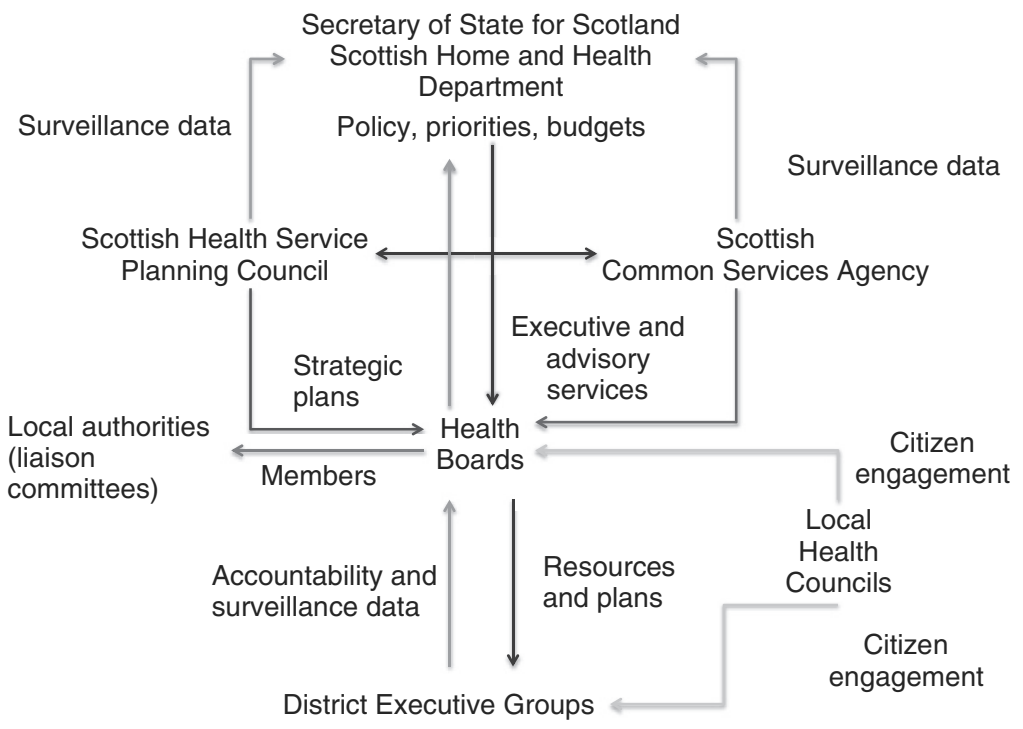

Figure 2.2 Representation of Scottish NHS as envisioned after 1974 reorganisation

boards - and relations between various parts of the service functioned relatively harmoniously (see Fig. 2.2). ${ }^{130}$

Finally, in Wales, the new NHS arrangements appeared as something of a mix of the English and Scottish variants structurally, but the Welsh system leaned much more towards the English version in tensions between central and local institutions (Fig. 2.3). ${ }^{131}$

Although the new structural differences between England, Scotland, and Wales probably had considerable day-to-day effects, the exact relationships of different bodies involved are less important to the story of diabetes care than the fact that, across Britain, the position of the $\mathrm{MOH}$ was removed. ${ }^{132}$ Eventually, former $\mathrm{MOH}$ were incorporated into the NHS as managers and service analysts, and their earlier clinical service responsibilities fell to GPs and hospitals. Some of the new Community Physicians did play important roles in piloting experiments with GP care in various parts of the country. ${ }^{133}$ But the removal of MOHs provided an important space for GPs to claim 'community' practice and service integration as their own field, with visions like that of Reid discussed in the previous chapter now no longer possible. 


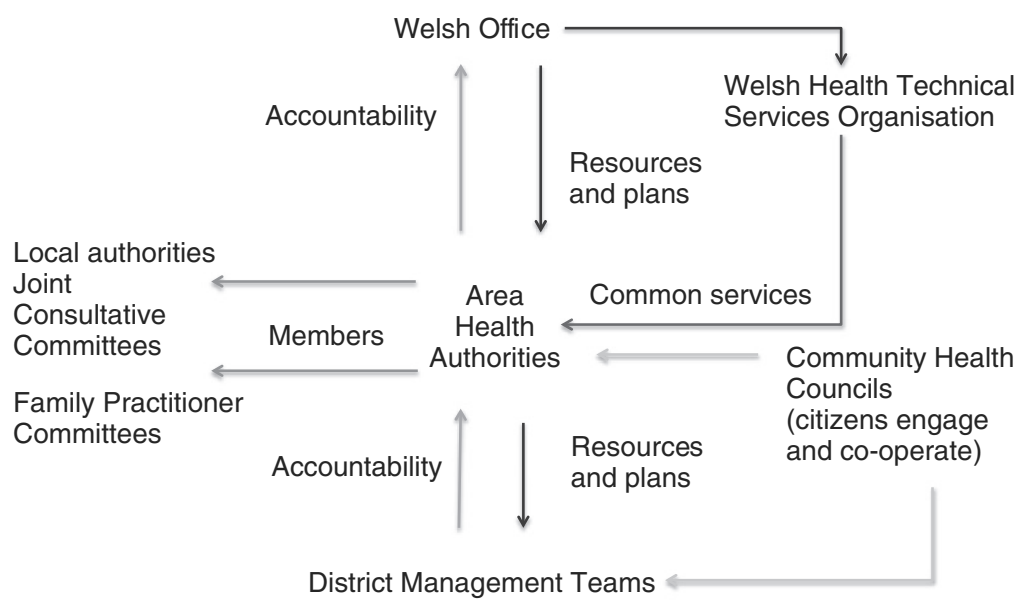

Figure 2.3 Representation of Welsh NHS as envisioned after 1974 reorganisation

Conclusion: political support and questions

Rather than settling issues of NHS structure, the 1974 reorganisation merely marked the beginning of a 'continuous revolution' in service policy and dynamics. ${ }^{134}$ Nonetheless, although perhaps considered unsuccessful from this policy perspective, the alterations ushered in by the 1974 reforms had a considerable impact on British medicine. The abolition of the $\mathrm{MOH}$ role, for instance, enabled GPs to expand into preventive health work, and - supported by new technologies and new understandings of diabetes management - GPs increasingly considered diabetes as a legitimate responsibility of primary care.

With clinics facing increasing pressures on resources and deteriorating working conditions, specialists were also leading figures in promoting structured programmes of community care for diabetes during the 1970s and 1980s. By the early 1990s, various forms of GP care had spread widely, if not deeply, across Britain as practitioners experimented with forms of systematic and integrated care in major towns and cities. Community schemes, mini-clinics, GP care based on diabetes days or hours, and travelling clinics could be found everywhere from Kirkcaldy to Poole and from Norwich to Cardiff. Schemes spread despite warnings about efficacy. As one exchange of letters to the British Medical Journal $(B M J)$ indicated, conflict about the devolution of responsibilities to 
GPs could be fierce. In a co-authored letter reviewing the extant literature in 1984, the GP Brian Hurwitz and the renowned epidemiologist John Yudkin proposed that motivated general practice care could match hospital provision, but only when oversight mechanisms were in place. Without these procedures, 'routine general practitioner care ... increase $[\mathrm{d}]$ the risk of poorer diabetic control and higher overall morbidity and mortality'. Therefore, Hurwitz and Yudkin concluded, 'a global policy of encouraging general practitioners to set up diabetic mini-clinics' was 'unlikely ... [to] provide a solution to improving diabetic supervision' and 'reduce the number of patients attending hospital clinics. ${ }^{135}$ Their view formed part of an exchange sparked by an editorial entitled 'Diabetes care: whose responsibility?', in which various forms of GP care were unfavourably compared with one another. ${ }^{136}$ In reply to suggestions that GP management in certain locations was 'unacceptable', some correspondents argued that the GP had a duty to ensure follow-up provision regardless of negative assessments, whilst others turned on consultants and declared unsupportive and inattentive hospital staff to be a major block to good general practice care. ${ }^{137}$

Two major points emerge from this exchange. The first is that even by 1984, doctors of all stripes saw GP care as an important innovation. It was one that demanded investigation, but which was to be pursued regardless of results. Conflict had in some areas led to passive resistance and uneven distribution of care, but was not allowed to derail programmes. In places like Sheffield, for instance, whilst the energy and charisma of programme pioneers may have helped launch the scheme, it was the work of mobile specialist nursing staff that sustained such efforts by mediating tensions between GPs and consultants. ${ }^{138}$ On a national scale, efforts to promote this form of care received political backing by the late 1980s. As will be discussed in Chapters 4 and 6, the 'cost-effective' realm of primary care proved attractive to the second and third Thatcher administrations (1983-87, 1987-90), which were elected on platforms of public sector reform and reduced central expenditure. Moreover, GP contracts of the early 1990s contained specific financial recompense for running general practice clinics for chronic disease, including diabetes. Such political support for the repositioning of general practice, with diabetes as a major element, undoubtedly underpinned the spread of GP care in spite of medical reservations. ${ }^{139}$

The second point of interest emerges from the conclusions for how to improve general practice care. Hurwitz and Yudkin themselves 
suggested that the computerisation of schemes - which would prompt GPs when follow-up was needed, and demand results from various tests - might offer one route to improvement, along with further education. ${ }^{140}$ This suggestion drew a sharper line around various managerial mechanisms that had medical professionals as their subject. ${ }^{141}$ The very earliest GP schemes involved formal referral and care protocol to divide responsibility for patients and to guide decisions about appropriate expertise and decision-making. Recall systems had been in place since the 1970s, and were designed to remind practitioners to proactively make appointments for patient follow-up. Record cards, seemingly inert devices on which to inscribe results, were also intended to prompt clinicians into undertaking certain actions, and moved around the system to facilitate division of labour and clinical review. Structuring diabetes management, in other words, involved structuring the work of the clinician as much as the care received by the patient.

Whilst the drives for managerial technologies that routinised care had been in play for some time, the move to divide responsibility for diabetes management across various sites had thrust them into the centre of diabetological discourse and practice. The repositioning of this work as preventive and public-health-oriented in the 1980s and early 1990s also made national forms of management even more of a priority. It will be these developments - the creation of managerial technologies in structured and shared care schemes, the formalisation of diabetes management as a public health problem, and the politicisation of national structures of healthcare governance - that will now form the interests of Chapters 3, 4, and 5 respectively.

\section{Notes}

1 TNA, BD 18/793, questionnaire completed by Dr D. C. Lewin, 'Review of diabetic service', 5 August 1964, p. 4.

2 M. D. Moore, 'Reorganising chronic disease management: diabetes and bureaucratic technologies in post-war British general practice', in M. Jackson (ed.), The Routledge History of Disease (London: Routledge, 2017), p. 460.

3 R. D. Hill, 'Community care service for diabetics in the Poole area', $B M J$, 1:6018 (1976), 1139.

4 Such as asthma or 'chronic rheumatism': J. Fry, Common Diseases: Their Nature, Incidence and Care, 2nd edition (Lancaster: MTP Press Limited, 1979), pp. 22-4. 
5 See Chapter 3.

6 I. Loudon and M. Drury, 'Some aspects of clinical care in general practice', in I. Loudon, J. Horder, and C. Webster (eds.), General Practice under the National Health Service, 1948-1997 (Oxford: Oxford University Press, 1998), pp. 103-4.

7 A. Digby, The Evolution of British General Practice, 1850-1948 (Oxford: Oxford University Press, 1999), pp. 332-7.

8 Loudon and Drury, 'Some aspects of clinical care', pp. 106-8.

9 D. G. French, 'Advances in general practice', The Practitioner, 183:1096 (1959), 514. One study estimated that patients with diabetes consulted almost twice as frequently as patients without the condition (once age and sex-matched): C. T. Andrews, 'A survey of diabetes in west Cornwall', BMJ, 1:5016 (1957), 431.

10 I. H. Redhead and J. J. A. Reid, 'Diabetic clinics and the general practitioner', The Lancet, 281:7273 (1963), 159-60.

11 G. Smith and M. Nicolson, 'Re-expressing the division in British medicine under the NHS: the importance of locality in general practitioners' oral histories', Social Science and Medicine, 64:4 (2007), 938-48.

12 'Clinical diabetes mellitus', Journal of the Royal College of General Practitioners (JRCGP), 15:4 (1968), 307. Clinical assistantships were common across different areas of medicine: E. O. Evans and I. McWhinney, 'General practitioner and the general hospital', BMJ, 1:5384 (1964), 688-90.

13 J. Horder, 'Conclusion', in Loudon, Horder, and Webster (eds.), General Practice under the National Health Service, p. 281.

14 G. Rivett, From Cradle to Grave: Fifty Years of the NHS (London: King's Fund, 1998), pp. 163-4.

15 This remained the case until 1982, when voluntary vocational training became mandatory: D. Pereira Gray, 'Postgraduate training and continuing education', in Loudon, Horder, and Webster (eds.), General Practice under the National Health Service, pp. 182-204.

16 Rivett, From Cradle to Grave, pp. 163-4.

17 Redhead and Reid, 'Diabetic clinics and the general practitioner', p. 160. As this survey indicated, GPs themselves also admitted a lack of confidence.

18 TNA, BD 18/793, questionnaire completed by Dr F. W. Thomas, 'Review of diabetic service, 8 September 1964, p. 3.

19 C. H. Stewart-Hess, 'The management of maturity onset diabetes in general practice', JRCGP, 23:137 (1973), 841-60.

20 Royal College of General Practitioners Archives, London, MSS, B Fry C6-1 (i), J. Fry, 'The management of maturity onset diabetes in a general practice (1951-1971)', undated, p. 11.

21 Andrews, 'A survey of diabetes in west Cornwall', p. 431. 
22 R. F. L. Logan, General Register Office Studies on Medical and Population Subjects, 7 (London: HMSO, 1953). See the consultation and 'patients consulting' numbers in table 2, p. 47.

23 Redhead and Reid, 'Diabetic clinics and the general practitioner', pp. 159-60; Andrews, 'A survey of diabetes in west Cornwall'.

24 Interview with J. Hill conducted by the University of Oxford, 1 October 2004, available at: www.diabetes-stories.com/transcript.asp?UID =19 (accessed April 2017).

25 G. Forsyth and R. Logan, Gateway or Dividing Line? A Study of Hospital Outpatients in the 1960s (Oxford: Oxford University Press for the Nuffield Provincial Hospitals Trust, 1968), pp. 59-62.

26 Ibid., p. 61. Diabetes was a prominent example.

27 'Diabetes mellitus - incidence, causation, management', Proceedings of the Royal Society of Medicine, 55:3 (1962), 211.

28 Ibid.

29 H. Keen, 'The family doctor and the diabetic', The Practitioner, 194:1160 (1965), 244.

30 L. A. Pike, 'A general practitioner looks at diabetes', Public Health, 77:3 (1963), 169.

31 Keen, 'The family doctor and the diabetic', p. 246.

32 Ibid., p. 244.

33 See Chapter 1.

34 Especially if GPs were given access to pathological laboratories: 'Annual meeting, Oxford: scientific sections', BMJ, 2:5353 (1963), 374.

35 Pike, 'A general practitioner looks at diabetes', p. 169.

36 Ibid., p. 168.

37 Ibid., pp. 167-8.

38 Ibid., p. 165. On associative prediction vs causation: G. M. Oppenheimer, 'Profiling risk: the emergence of coronary heart disease epidemiology in the United States (1947-70)', International Journal of Epidemiology, 35:3 (2006), 720-30, esp. pp. 725-7.

39 On Darbishire House: M. Perry, 'Academic general practice in Manchester under the early National Health Service: a failed social medicine experiment', Social History of Medicine, 13:1 (2000), 111-29.

40 R. F. L. Logan, 'Control of chronic disease in general practice and industry', Journal of the College of General Practitioners (JCGP), 11:S.1 (1966), 94.

41 Ibid., pp. 94-5.

42 Ibid., p. 95.

43 Ibid., p. 96.

44 Ibid., p. 99.

45 D. Armstrong, Political Anatomy of the Body: Medical Knowledge in Britain in the Twentieth Century (Oxford: Oxford University Press, 1983). 
$46 \mathrm{H}$. Valier and C. Timmermann, 'Clinical trials and the reorganization of medical research in post-Second World War Britain', Medical History, 52:4 (2008), 493-510, esp. p. 498.

47 See the discussion of the College of General Practitioners below.

48 C. Webster, 'The politics of general practice', in Loudon, Horder, and Webster (eds.), General Practice under the National Health Service, pp. 28-31.

49 S. McLaurin and D. F. Smith, 'Professional strategies of Medical Officers of Health in the post-war period - 2: "progressive realism": the case of R. J. Donaldson, MOH for Teeside, 1968-1974', Journal of Public Health Medicine, 24:2 (2002), 130-5.

50 K. Hodgkin, 'Good general practice without routine screening examinations', JCGP, 11:S.1 (1966), 100.

51 Ibid., p. 101.

52 A. L. Cochrane, 'A medical scientist's view of screening', Public Health, 81:5 (1967), 207-13; 'Can we prevent it?', The Lancet, 288:7474 (1966), 1171-2.

53 J. Malins, Clinical Diabetes Mellitus (London: Eyre \& Spottiswood, 1968), pp. 138-9, 190-1, 236-7, 447-9.

54 D. L. Crombie, 'Preventive medicine and presymptomatic diagnosis', JRCGP, 15:5 (1968), 346; H. Keen, G. Rose, D. A. Pyke, D. Boyns, C. Chlouverakis, and S. Mistry, 'Blood sugar and arterial disease', The Lancet, 286:7411 (1965), 505-8.

55 TNA, MH 133/271, internal memo by CHSC staff, 'Diabetic screening', 29-30 November 1961.

56 G. O’Hara, From Dreams to Disillusionment: Economic and Social Planning in the 1960s (Basingstoke: Palgrave Macmillan, 2007), pp. 167-204.

57 C. Webster, The Health Services since the War, vol. 2: Government and Health Care: The British National Health Service, 1958-1979 (London: HMSO, 1996), p. 804. See the table 'Appendix 3.5', which outlines current and capital expenditure on the service in real terms according to a special NHS deflationary index. On the economy: P. Howlett, 'The "Golden Age”, 1955-1973', in P. Johnson (ed.), Twentieth Century Britain: Economic, Social and Cultural Change (London: Longman, 1994), pp. 320-6; see figure 18.3, which outlines GDP deviation from a trend rate of 2.8 per cent per annum.

58 Otherwise known as the Hospital Plan: O’Hara, From Dreams to Disillusionment, pp. 184-5.

59 Rivett, From Cradle to Grave, pp. 179-80. A separate committee was established in Scotland a year earlier under J. H. F. Brotherston, Chief Medical Officer for the Scottish Home and Health Department (SHHD). The reports were organised differently, the structures suggested for reform varied, and there appeared 'greater suspicion' of new organisational 
arrangements in Scotland: 'Cogwheel in Scotland', BMJ, 4:5841 (1972), 661-2. Nonetheless, the pressures underpinning the committees were shared. Moreover, the Chief Medical Officers who chaired the respective groups co-operated closely, and the principles and conclusions of the reports were very similar: Webster, The Health Services since the War, vol. 2, pp. 312-13.

60 Ministry of Health, First Report of the Joint Working Party on the Organisation of Medical Work in Hospitals (London: HMSO, 1967), paras. 27-31.

61 Ibid., para. 24.

62 Ibid., para. 14(b); see also paras. 33-41 and 55-67. Clinical divisions were groups of clinicians linked through specialisms where tools, spaces, and staff were common.

63 J. S. Stewart, 'Cogwheel: a physician's view of a local version', $B M J$, 4:5680 (1969), 420-3.

64 P. Addison, No Turning Back: The Peacetime Revolutions of Post-War Britain (Oxford: Oxford University Press, 2010), pp. 149-56.

65 R. Klein, 'The crises of the welfare states', in R. Cooter and J. Pickstone (eds.), Medicine in the Twentieth Century (Amsterdam: Rodopi, 2000), pp. 155-70; B. Clift and J. Tomlinson, 'Negotiating credibility: Britain and the International Monetary Fund, 1956-1976', Contemporary European History, 17:4 (2008), 545-66.

66 See Chapters 4 and 6.

67 See discussion later in this chapter.

68 Rivett, From Cradle to Grave, pp. 274, 272-5.

69 The Office of Health Economics was founded by the British Pharmaceutical Industry in 1962: W. Laing and R. Williams, Diabetes: A Model for Health Care Management (London: Office of Health Economics, 1989), p. 2. The Patients' Association was created by a part-time teacher in 1963: A. Mold, Making the Patient-Consumer: Patient Organisations and Health Consumerism in Britain (Manchester: Manchester University Press, 2015), pp. 29-34.

70 'Inquiry is urged into hospital queues', The Times, 13 August, 1968, p. 2; Forsyth and Logan, Gateway or Dividing Line?, pp. 2-3, 59-62.

71 J. M. Wilks, 'Diabetes - a disease for general practice', JRCGP, 23:126 (1973), 46.

72 Hill, 'Community care service for diabetics', p. 1137.

73 P. A. Thorn and R. G. Russell, 'Diabetic clinics today and tomorrow: mini-clinics in general practice', BMJ, 5865:2 (1973), 536.

74 Hill, 'Community care service for diabetics', p. 1139.

75 J. M. Malins and J. M. Stuart, 'Diabetic clinic in a general practice', BMJ, 5780:4 (1971), 161.

76 I. Benett, 'Diabetes mini-clinic', JRCGP, 37:307 (1988), 76-7.

77 Thorn and Russell, 'Diabetic clinics today and tomorrow'. 
78 Hill, 'Community care service for diabetics'.

79 Loudon and Drury, 'Some aspects of clinical care', pp. 109-10; Fry, 'The management of maturity onset diabetes', p. 1.

80 C. E. Upton, 'Diabetic community care', The Practitioner, 215:1284 (1975), 83.

81 A. Cartwright, Patients and their Doctors: A Study of General Practice (London: Routledge and Kegan Paul, 1967), pp. 44-52.

82 Malins and Stuart, 'Diabetic clinic in a general practice'.

83 Stewart-Hess, 'The management of maturity onset diabetes in general practice', p. 859.

84 For a history of familial rhetoric: R. Hayward, The Transformation of the Psyche in British Primary Care, 1870-1970 (London: Bloomsbury Academic, 2014), pp. 33-6, 57-9.

85 Rivett, From Cradle to Grave, pp. 90-1; T. Osborne, 'Epidemiology as an investigative paradigm: the College of General Practitioners in the 1950s', Social Science and Medicine, 38:2 (1994), 318.

86 Osborne, 'Epidemiology as an investigative paradigm', p. 318. Histories of general practice have often seen the Collings Report of 1950 as the most damning assessment of general practice, and one connected with the College's creation: J. S. Collings, 'General practice in England today: a reconnaissance', The Lancet, 255:6604 (1950), 555-79. C. Webster, The Health Services since the War, vol. 1: Problems of Health Care: The National Health Service before 1957 (London: HMSO, 1988), pp. 356-7.

87 For instance: S. Taylor, Good General Practice: A Report on a Survey (London: Oxford University Press, 1954); CHSC, The Field Work of the Family Doctor: Report of the Sub-Committee (London: HMSO, 1963); RCGP, The Future General Practitioner (London: RCGP, 1972).

88 'Undergraduate education conference, 7th May, 1961', JCGP, 5:2 (1962), 290-5. Osborne, 'Epidemiology as an investigative paradigm', pp. 318-19; Armstrong, Political Anatomy of the Body, pp. 73-5.

89 J. A. Pridham, 'Future trends in general practice', JCGP, 5:4 (1962), 537. For critiques of the NHS as overly bureaucratic: D. Wright, S. Mullally, and M. C. Cordukes, "Worse than being married": the exodus of British doctors from the National Health Service to Canada, c.1955-75, Journal of the History of Medicine and Allied Sciences, 65:4 (2010), 546-75.

90 Taylor, Good General Practice, p. 445.

91 RCGP, The Future General Practitioner.

92 Malins and Stuart, 'Diabetic clinic in a general practice'.

93 Thorn and Russell, 'Diabetic clinics today and tomorrow', p. 534.

94 A. P. Kratky, 'An audit of the care of diabetics in one general practice', JRCGP, 27:182 (1977), 536. 
95 R. J. Jarrett, H. Keen, J. H. Fuller, and M. McCartney, 'Worsening to diabetes in men with impaired glucose tolerance ("borderline diabetes")', Diabetologia, 16:1 (1979), 25-30.

96 R. J. Jarrett, H. Keen, J. H. Fuller, and M. McCartney, 'Treatment of borderline diabetes: controlled trial using carbohydrate restriction and phenformin', BMJ, 2:6091 (1977), 861-5.

97 J. H. Fuller, M. J. Shipley, G. Rose, R. J. Jarrett, and H. Keen, 'Coronaryheart-disease risk and impaired glucose tolerance: the Whitehall study', The Lancet, 315:8183 (1980), 1373-6.

98 P. J. Burrows, P. J. Gray, A.-L. Kinmonth, D. J. Payton, G. A. Walpole, R. J. Walton, D. Wilson, and G. Woodbine, 'Who cares for the patient with diabetes? Presentation and follow-up in seven Southampton practices', JRCGP, 37:295 (1987), 68.

99 Though animal experiments did feature into some discussions: K. M. West, 'Hyperglycaemia as a cause of long-term complications', in H. Keen and J.Jarrett (eds.), Diabetic Complications, 2nd edition (London: Edward Arnold, 1982), pp. 13-18.

$100 \mathrm{H}$. Al Sayegh and R. J. Jarrett, 'Oral glucose-tolerance tests and the diagnosis of diabetes: results of a prospective study based on the Whitehall survey', The Lancet, 314:8140 (1979), 431-3.

101 Ibid.

102 D. Armstrong, 'The rise of surveillance medicine', Sociology of Health and Illness, 17:3 (1995), 393-404.

103 See the broadly supportive response, with caveats: 'Impaired glucose tolerance and diabetes - WHO criteria', BMJ, 281:6254 (1980), 1512-13.

104 J. S. Yudkin, B. J. Boucher, K. E. Schopflin, B. T. Harris, H. R. Claff, N. J. D. Whyte, B. Taylor, D. H. Mellins, A. B. Wootliff, J. G. Safir, and E. J. Jones, 'The quality of diabetic care in a London health district', Journal of Epidemiology and Community Health, 34:4 (1980), 277-80.

105 Interview with Professor Whittaker conducted by the author. Professor Whittaker is a retired consultant diabetologist who worked within major centres of diabetes care and research between the 1970s and 2000s.

106 R. J. Jarrett, Diabetes Mellitus (London: Croom Helm, 1987), pp. 1-3; J. A. Greene, Prescribing by Numbers: Drugs and the Definition of Disease (Baltimore: Johns Hopkins University Press, 2007).

107 Burrows et al., 'Who cares for the patient with diabetes?'; M. T. Wojciechowski, 'Systematic care of diabetic patients in a general practice', JRCGP, 32:242 (1982), 531-3.

108 Wojciechowski, 'Systematic care of diabetic patients in a general practice', pp. 531, 533.

109 Kratky, 'An audit of the care of diabetics in one general practice', p. 539. 
110 R. D. Hill, Diabetes Health Care: A Guide to the Provision of Health Care Services (London: Chapman and Hall, 1987), pp. 91-100, quotations at pp. 91-2.

111 UK Prospective Diabetes Study Group, 'Intensive blood glucose control with sulphonylureas or insulin compared with conventional treatment and risk of complications in patients with type 2 diabetes (UKPDS 33)', The Lancet, 352:9131 (1998), 837-53.

112 And questions still abound about the most useful metabolic markers for care and translating trial results into practice: J. S. Yudkin, B. Richter, and E. A. M. Gale, 'Intensified glucose lowering in type 2 diabetes: time for a reappraisal', Diabetologia, 53:10 (2010), 2079-85.

113 M. Hammersley, M. Holland, S. Walford, and P. Thorn, 'What happens to defaulters from a diabetic clinic?’, BMJ, 291:6505 (1985), 1330-2.

114 Oppenheimer, 'Profiling risk'.

115 See Chapter 3.

116 RCGP, Prevention of Arterial Disease in General Practice: A Report of a Sub-Committee of the Royal College of General Practitioners' Working Party on Prevention, Report from General Practice, 19 (London: RCGP, 1981), p. 1.

117 Though note C. Waine, Why Not Care for your Diabetic Patients?, 2nd edition (London: RCGP, 1988), p. 3.

118 RCGP, Prevention of Arterial Disease in General Practice, pp. 7, 1.

119 Ibid., p. 7.

120 J. T. Hart, 'A new kind of doctor', Journal of the Royal Society of Medicine, 74:12 (1981), 871-83.

121 Pike, 'A general practitioner looks at diabetes'; M. Gray and G. Fowler (eds.), Preventive Medicine in General Practice (Oxford: Oxford University Press, 1983).

122 For instance, hypertension was reframed as a quantitative deviation of physiology after the 1950s, just as diabetes was: C. Timmermann, 'A matter of degree: the normalization of hypertension, c.1940-2000', in W. Ernst (ed.), Histories of the Normal and the Abnormal: Social and Cultural Histories of Norms and Normativity (London: Routledge, 2006), pp. 245-61. For asthma: M. Jackson, Asthma: The Biography (Oxford: Oxford University Press, 2009), esp. pp. 183-8.

123 M. Lawrence, 'All together now', JRCGP, 38:7 (1988), 296-302, esp. p. 297.

124 J. T. Hart, 'Specialization in general practice', JRCGP, 30:4 (1980), 218.

125 Such as in computerisation of clinics: G. Brownbridge, A. Evans, M. Fitter, and M. Platts, 'An interactive computerized protocol for the management of hypertension: effects on the general practitioner's clinical behaviour', JRCGP, 36:5 (1986), 198-202. 
126 J. Gedney, 'Reconstruction of general practice', BMJ, 290:6478 (1985), 1350; Lawrence, 'All together now'.

127 Rivett, From Cradle to Grave, pp. 209-11; M. Calnan, Preventing Coronary Heart Disease: Prospects, Policies, and Politics (London: Routledge, 2002 [1991]).

128 Webster, The Health Services since the War, vol. 2, pp. 321-73, 451-579.

129 Ibid., pp. 546-63, esp. p. 551.

130 C. Webster, The National Health Service: A Political History (Oxford: Oxford University Press, 1998), p. 92.

131 Webster, The Health Services since the War, vol. 2, pp. 572-4.

132 On the decline of MOHs, cf. J. Lewis, What Price Community Medicine? The Philosophy, Practice and Politics of Public Health since 1919 (Brighton: Wheatsheaf, 1986); J. Welshman, 'The Medical Officer of Health in England and Wales, 1900-1974: watchdog or lapdog?', Journal of Public Health Medicine, 19:4 (1997), 443-50; M. Gorsky, 'Local leadership in public health: the role of the Medical Officer of Health in Britain, 1872-1974', Journal of Epidemiology and Community Health, 61:6 (2007), 470-1.

133 Interview with Professor Davies conducted by the author. Professor Davies is a retired academic epidemiologist and health authority member.

134 Webster, The National Health Service, pp. 140-214.

135 B. Hurwitz and J. Yudkin, 'Diabetes care: whose responsibility?', BMJ, 289:6450 (1984), 1000.

136 P. Home and S. Walford, 'Diabetes care: whose responsibility?, BMJ, 289:6447 (1984), 713-14.

137 R. Pietroni, 'Diabetes care: whose responsibility?', BMJ, 289:6450 (1984), 1001; G. F. Morgan, D. A. Cadman, P. H. Edwards, T. C. O’Dowd, and R. H. Davis, 'Diabetes care: whose responsibility?', BMJ, 289:6454 (1984), 1309-10.

138 E. Wilkes and E. E. Lawton, 'The diabetic, the hospital and primary care', JRCGP, 30:213 (1980), 199-206; interview with M. MacKinnon conducted by the University of Oxford, 23 April 2007, available at: www.diabetes-stories.com/interview.asp?UID=62 (accessed April 2017).

139 Not that general practice attracted significantly more resources. The current expenditure of general practice in 1976-77 was roughly 6.44 per cent of total NHS current expenditure, compared with 7.08 per cent in 1987-88. These figures were produced by taking the proportion of NHS expenditure allocated to family practitioner services, then calculating the percentage of this allocation spent on general medical services (as opposed to pharmaceutical, general dental, and ophthalmic services). Figures for 1976-77 were 22.6 per cent of NHS current expenditure on family practitioner services, and 28.5 per cent of this allocated to general medical services $(22.6 \times 0.285=6.44)$ : Webster, The Health Services since 
the War, vol. 2, appendices 3.9 and 3.11. Figures for 1987-88 were 24 per cent and 29.5 per cent respectively $(24 \times 0.285=7.08)$ : Secretaries of State for Social Services, Promoting Better Health, p. 7.

140 Hurwitz and Yudkin, 'Diabetes care'.

141 The Poole scheme was already experimenting with computerisation: Home and Walford, 'Diabetes care'. 